\title{
The Monographic Series Approval Plan: An Attempt to Refine Purchasing of Books in Series
}

\section{Heather S. Miller}

\begin{abstract}
Librarians often place standing orders for monographic series in order to ensure complete holdings. This can result in the acquisition of inappropriate materials. It is possible to include books in series on a comprehensive approval plan that will permit return rights and still obtain a higher discount. However, some books might not fit the institution's profile and thus will not be supplied. Some control of the series is also lost. A third alternative is presented here: an approval plan limited to monographic series.
\end{abstract}

L

ibrarians establish standing orders for monographic series to assure complete holdings. Unfortunately, this completeness can include unneeded, unwanted, or unsuitable materials if publishers broaden, narrow, or otherwise change the scope of a series or include reprints. Even books worthwhile in themselves might be unneeded if the subjects are adequately covered by other materials in the library. Series themselves might have changed focus, yet the materials continue to arrive and be added to the collections. This can be a drain on limited resources.

It is certainly possible for bibliographers to review all incoming standing order books to monitor the quality and suitability of materials, but this does not allow them to reject books already received.

Monographic series might be included in general approval plans, but individual titles will be subject to the parameters of the profile and therefore might not neces- sarily be supplied. Price limits might also exclude some volumes. A series might move to a publisher excluded from the plan. The profile of an individual volume might simply fail to match and the book will not be supplied.

In this paper, an alternative method of managing the purchase of volumes in monographic series is offered. The purpose is both to ensure comprehensive review of all volumes in specified monographic series and to allow return of volumes not wanted for the library's collections.

\section{Literature Review}

While there is an extensive body of literature on approval plans, studies limited to monographic series in this context are few. Alessi and Goforth (1988), Warzala (1991), and Rouzer (1995) explored the use of approval plans to supply books in series. Along with listing 9 advantages of 
(1991), and Rouzer (1995) explored the use of approval plans to supply books in series. Along with listing 9 advantages of approval plans as mechanisms for acquiring newly published monographs, Alessi and Goforth also point out that "series control is an integral part of every approval vendor's operation" $(1988,25)$. Se ries control is intended to ensure that books published in series are identified, series title changes noted, moves to new publishers followed, etc., so that the entire sequence of volumes published in a given series can be traced. Approval vendors, for instance, need to do this in order to avoid duplicating approval books their customers receive on standing order.

Alessi and Goforth list several methods that permit subsequent books in series to be supplied on an approval plan: (1) allow them to be supplied as they fit the profile; (2) set up an "approval standing order" to ensure that all volumes in a given series will be supplied even if they do not fit the profile; or (3) establish a similar arrangement in which notification forms rather than books for titles in series are supplied. Advantages they cite in allowing an approval vendor to supply books in series include: (1) the option of limiting receipts to only those titles that match the profile, (2) the opportunity to review and reject individual books, and (3) lower prices. Disadvantages include the fact that certain titles cannot be supplied on an approval basis at all, and potential loss of some part of series control. Alessi and Goforth predicted that “. . standing orders and approval plans will become more interdependent in libraries as automated systems are implemented" (p. 40).

Warzala (1991) studied several specific series and concluded that "the qualitative approval review process might be unnecessarily labor-intensive" (p. 325) for series of limited variability. These might be more efficiently handled by standing order. However, “.. series that are inconsistent in quality, scope, subject and/or intended level of readership might be acquired in a more rational manner using approval plans" (p. 325). He advocates either careful use of standing orders or inclusion on general approval plans based on individual series characteristics.

Rouzer (1995) conducted another study of approval plan versus standing order for books in series at the Eisenhower Library at Johns Hopkins University. Titles published outside the United States were found to be supplied more quickly by standing order, whereas most United States university press titles were supplied more rapidly on approval. Two-hundred sixteen series standing orders were canceled and allowed to come in on the library's comprehensive approval plan. The Acquisitions Department tracked 50 series for which bibliographers wanted all volumes and firm ordered any volumes not supplied on approval. He concluded that ". . a wellprofiled approval plan was a better selection tool than a standing order" (p. 401).

The conclusions reached by these authors point to the well-known advantages of approval plans for acquiring books for which the subject is relevant to the library's subject profile and standing orders for comprehensive coverage. However, there is little reported on the "approval standing order," which combines comprehensive receipt with the flexibility to return those volumes not deemed es. sential to the library's collection.

\section{Project Definition}

At the State University of New York at Albany Libraries, monographic series standing orders were perceived as an area of acquisition that had taken on a life of its own due to its ongoing nature and lack of periodic review. In an attempt to save acquisitions dollars and gain control over the situation, the library staff embarked on an experiment: the monographic series approval plan would be set up entirely separately from the library's general approval plan. Neither the literature search nor discussion with vendors revealed any indication that an arrangement quite like this had been reported before. Thus, it was an experiment for both the library and the vendor, who saw this as an opportunity to work with the library to develop a service that might be useful to others. In 1993, 
a monographic series approval plan was designed to function as an approval plan for specified monographic series, which until then were acquired on standing order.

\section{Setting Up the Plan}

Nine of 15 bibliographers expressed interest in this experiment, with participation being entirely voluntary. Only one vendor, Academic Book Center (not the library's general approval plan supplier), was interested. A list was generated showing all 1,496 monographic series titles on standing order. It was then broken out by fund code. All bibliographers received lists of monographic series being obtained on each fund code they managed. Some felt no need to review and possibly return the individual volumes in these series, but others selected certain titles that they wished to receive on an approval basis. Each bibliographer assigned appropriate weight to the following criteria: perceived quality of the publications, overall amount of material received for a given subject, usage of volumes already held by the library, relevance to the curriculum or research, and price. Bibliographers were particularly likely to select series titles where experience has shown that not all volumes in a series were relevant to the library collection. Of the 111 titles selected by the bibliographers, 20 were eliminated because they were received on a membership or subscription basis, or were not distributed in the United States. The resulting list of 91 titles (6\% of the total) was sent to Academic Book Center for inspection. A representative of the vendor visited the library and met with acquisitions and collection development personnel to outline the proposed plan, which was to include only the monographic series specified on the final list. A $12 \%$ discount and free shipping were to be offered along with return privileges.

Prior to implementation, it was necessary to cancel existing standing orders for the included titles. This was done by Academic Book Center, using the library's letterhead. The Acquisitions Department provided the vendor with an accurate list of titles, purchase order numbers, and current suppliers. The cancellation letters requested that written confirmation be sent to the library with a note of the last volume to be supplied on the standing order. It was also necessary to continue to block these titles on other existing approval plans.

To no one's great surprise, several months passed and the library received only a handful of confirmations, with none indicating the last volume. Prodding by librarians eventually resulted in receipt of all of the cancellations over the next several months. In addition, the new vendor indicated a number of additional titles that could not be supplied on an approval basis. The list was shrinking and the project was going nowhere.

Another difficulty was encountered with some cancellations. Some suppliers reserve as much as 90 days after cancellation during which material already in process must be accepted by the library. There was some disagreement as to when the 90-day period began-at the date of the letter, the receipt of the letter, or several weeks later when the canceling vendor finally dealt with the cancellations. The determination, for each series, of the beginning volume on the approval plan was fraught with difficulties relative to the grace periods, especially materials sent even after the end of the grace period.

Online records were updated. Each online record carries a two-part order type that indicates the material type. A new order type was created for this project: "STANDI.APPRO" (for standing order/approval). Each record also carries a vendor code linking the order record to the vendor record containing full vendor information. This code was changed as necessary to reflect the approval vendor. It was decided not to change the fund code, but to continue using the standing order fund codes already in these records because they might become standing orders again. Moreover, no one thought of these as anything other than standing orders albeit with return privileges. Last, records for those titles that the bibliographers requested on approval, but which the 
vendor could not supply, were annotated and the reason for nonsupply recorded.

\section{Developing Procedures}

It was decided that staff in the Serials Unit would handle this material even though other approval plans are handled in the Monographs Unit. This was done to continue existing check-in procedures done in the Serials Unit. Serials check-in differs from monograph check-in in the library's online system and allows the easy building of a series volume holding record. A unique ship-to address was created for these items for easy identification upon receipt. Procedures were also established for notifying bibliographers when books were received for their review. In September 1994, more than a year after exploration of the concept had begun, the library received its first shipment of books. The plan was finally operational.

\section{INITIAL RESULTS}

Overall, we considered the plan successful. We evaluated the plan first on the security of knowing that all books in a series were being sent and second on the flexibility offered for returning books not wanted. The ability to retum books not wanted led to dollar savings in the acquisitions budget as well as to a collection not burdened with books considered not relevant. For the 58 series titles on the plan, volumes came quickly and reliably. Bibliographers had the opportunity to reject items, which they did at an overall retum rate of $42 \%$.

Unfortunately, it was less successful for the supplier. Seven months after the plan started, the vendor stated that returns were so high that money was being lost on every book. The library's figures showed that return rates by series title ranged from $0 \%$ to $100 \%$. The discount was discontinued. Free shipping remained in place due to New York state contract requirements.

\section{Fine-Tuning the Plan}

Several options were discussed with the supplier: moving some or all titles to the library's regular approval plan, moving more regular standing orders to the monographic series approval plan supplier, receiving notification slips instead of books for titles with the highest return rates, and canceling titles with the highest return rates. Moving standing orders to the supplier was considered by the library, but ultimately not pursued, both because of the amount of work involved and the fact that these orders were being successfully serviced by other vendors. The bibliographers expressed interest in receiving slips, but were not eager to cancel titles with high return rates or to merge this plan into the general approval plan. To start the process, the vendor provided a list of seven titles with $50 \%$ or higher return rates and suggested that they be canceled. The bibliographers did not agree, although two of these titles eventually were changed to notification slips once that phase of the plan became operational. Meanwhile, the library canceled two other titles that also had high return rates.

In May 1995, the Acquisitions Department sent additional standing order series titles for potential inclusion to the vendor and learned that about half of the titles could be supplied on this approval plan. In mid-September, a memo was sent to bibliographers with a list of these titles for them to indicate which should be added to the plan. Responses were slow to arrive from the bibliographers, which was understandable given the shrinking staff and increasing workload experienced by everyone in the library. Nearly a year went by before those lists that were in hand were dealt with. Responses included requests to cancel titles, to add titles to the approval arrangement, to return several to regular standing order status, and, for various reasons, to change some fund codes in the library's system. It was at this point that the vendor's suggestion of receiving notification slips was first seriously explored.

In September 1996, a letter was sent to the vendor specifying changes and additions to the plan. Seventeen titles could not be supplied on an approval basis after all, which was a disappointment felt more 
keenly perhaps because of the small size of the plan, and because of the way titles included in the plan were individually selected by bibliographers. Notification slips were then added to the plan. Ultimately, only 14 of the 24 requested series titles were workable as notification slips because the publishers were not included in the vendor's approval plan.

Once again, it took time to affect changes, and it was March 1997 when the first notification slips were received. Like the physical volumes, the slips now are handled by the Serials Unit. Individual records for the monographs continued to be made for all items, including those represented by notification slips. Online files are searched carefully and duplication or potential duplication dealt with immediately. Slips for unique titles are then sent to appropriate bibliographers with cover notes identifying the slips (to make clear that these differ from other notification slips with different procedures) and asking them to indicate whether the books are wanted.

We do not foresee further major adjustments because all series that the bibliographers wish to receive by this means, and that the vendor is able to supply, are on the plan.

\section{ANalysis}

Our evaluation of the plan took into consideration a number of factors: the time frame, the opportunity to examine and return books, the opportunity for cost savings to the acquisitions budget, the chance for a more relevant collection, and the staff time invested in establishing the plan and its ongoing operation. It took much longer to establish a functioning plan than had been hoped. This was due to lengthy delays (largely on the library's part), the number of steps that had to be taken, and the press of other work in the Acquisitions Department. The bibliographers involved are very happy with the plan. They find it useful and enlightening to examine the books in these particular series. Many books were being returned, both saving money and refining the content of the collections. However, the vendor has been less than happy for the very same reason. The basic problem encountered was a fundamental difference in the bibliographers' approach to this plan compared to the vendor's approach. The bibliographers' ability to return books resulted in a far higher return rate than the vendor had anticipated.

A fair amount of time was invested in this project by staff both at the library and the supplier. Staff at the library did so in the hope of saving acquisitions money, as in fact it did (see table 1). During the period from September 1994 through August 1996, books in 44 series were shipped. Four series were discontinued by the publisher after being set up for approval. Eight others were included in the plan, but had no activity. Two-hundred sixteen books that would otherwise have been accepted on standing order and worth a total of $\$ 26,680.02$ were returned. These books came from 33 series titles from 19 publishers. All but three of the series were in the science, technology, or medical (STM) subject areas. The three non-STM areas accounted for only $\$ 299.48$ in returned books. Prices of re turned books ranged from a high of $\$ 590.00$ to a low of $\$ 27.72$, with an aver age of $\$ 123.52$. Twenty-seven books from eight publishers were priced over $\$ 200$. There were 5 series for which the one and only book shipped was returned, for a

TABLE 1

Summary of activity on the Monographic Series approval Plan SEPT. 1, 1994-AUG. 31, 1996

\begin{tabular}{lccc}
\hline \hline & No. & $\%$ & \multicolumn{1}{c}{ \% } \\
\hline Books returned & 216 & 42 & $26,680.20$ \\
Books kept & 294 & 58 & $31,590.85$ \\
\hline Total & 510 & 100 & $\$ 58,271.05$ \\
\hline
\end{tabular}


return rate of $100 \%$. Nevertheless, these series remain in place on the plan in order to receive and review future volumes as published.

During this period, the library retained slightly more books than were returned. There were 294 books kept for a total of $\$ 31,590.85$, with an average price of $\$ 107.45$. Of course, the loss of discount some months into the plan increased the total cost of the retained books by an estimated $\$ 2,000-3,000$, but did not negate the overall savings. Thus, of the books shipped, $58 \%$ were kept and $42 \%$ were returned. Nine series from five different non-STM publishers had no returns, for an acceptance rate of $100 \%$. In 7 of these cases, only 1 to 3 books were shipped, but in two cases 14 and 22 books were shipped. The series with 14 shipped and kept has since been returned to regular standing order status, but the other 8 series remain on the monographic series approval plan.

Has it been worthwhile? If staff time and shipping costs (for returning unwanted books) were calculated, one might very well doubt that it has. However, in an institution where salaries, postage, and acquisitions funds are inviolably separate, some staff cost is deemed worthwhile in order to save acquisitions funds. It becomes a question of what staff would have done otherwise with the time spent on establishing this project-in economic terms, the opportunity cost. The primary goal was to save acquisitions money and to refine collection content. Salaries and shipping costs are not part of the acquisitions budget and were considered in qualitative terms. As it was, both were absorbed without major effects. Perhaps more claiming might have been done, and perhaps more people might have stayed late. In fact, much of the time spent in establishing the plan was done by professional people whose workdays go on until they choose to end them. They absorbed tasks related to the plan without consciously omitting other responsibilities. Although the long time frame was frustrating on one level, the fact that the work was spread over two years and interspersed among other tasks meant that the project had little impact on daily work- flow. Some tasks, such as adding notes to records, were made quick and nearly automatic by the use of programmed function keys.

In several instances, the time spent on this project served more than one purpose. Acquisitions staff, in working on the records for these series, did general maintenance work on the records they encountered. By placing series books in the approval context, the monographic series approval plan provided bibliographers with a convenient, familiar venue for reviewing a type of material that had been receiving little oversight in recent years. In effect, all standing orders for monographic series were reviewed. Those standing orders that now remain are known to be appropriate (with some exceptions for subscription orders not transferable to the approval plan). Although at the end of two years only 5 standing orders ( $0.334 \%$ of the entire list of 1,496 titles) were canceled, 68 titles ( $4.5 \%$ of the entire list) were transferred to the approval plan to receive regular scrutiny.

This discussion also generated interest among the bibliographers in reviewing books arriving on true standing orders and that process has since been reestablished. Some bibliographers find this a useful way to monitor standing orders, determining whether they remain relevant to the collection and are worth the cost, as well as aiding their general knowledge of what is being published and going into the collection. Such reviews had once been in place, but had ceased some years earlier. Moreover, the investment of time in setting up the plan will not be repeated, so its cost will average out over the life of the plan. Ongoing time commitments for Acquisitions Department staff are little different from those required for regular standing orders. Bibliographers' time spent reviewing the books might be balanced by the reduction or elimination of other approval plans over the past few years. All involved, both acquisitions and collection development personnel, felt that it was a very useful project. Likewise, the vendor, viewing this plan as an experiment, found it worthwhile for the knowledge gained, 
despite the difficulty of making a profit. Recent conversations with the vendor indicate a willingness to continue the plan.

\section{CONCLUSION}

We expect to continue this plan because it provides selectivity combined with the security of knowing that no volumes will be missed. A significant amount of acquisitions money has been, and will continue to be, saved. The lack of a discount has been considered an acceptable cost to pay for the benefits realized. Serials control has been maintained in that the library knows what volumes are published in these series and is able to make and record its acquisition decision for each. Now that the plan is established and functioning smoothly, procedures for the Acquisitions Department are no more taxing than for monographic series on standing order.
Since the inception of the monographic series approval plan, the library's comprehensive approval plan has moved to a different vendor, who has indicated that it might be possible to include specific series in that plan. Interest from another vendor is an encouraging sign for the future viability of the monographic series approval plan and will be pursued.

\section{WoRKS CITED}

Alessi, D., and K. Goforth. 1988. Standing orders and approval plans: Are they compatible? The serials librarian 13: 21-41.

Rouzer, S. M. 1995. Acquiring monographic series by approval plan: Is the standing order obsolescent? Library acquisitions: practice \& theory 19: 395-401.

Warzala, M. 1991. Acquisition of monographic series: Approval plan versus standing order. Library acquisitions: practice o theory 15: 313-27. 